(2) Open Access Full Text Article

\title{
Retrospective Study of the Effects of Zoledronic Acid on Muscle Mass in Osteoporosis Patients
}

\author{
Chun-Feng Huang $\mathbb{1 D}^{1,2}$ \\ Ming-Shi Shiao ${ }^{3}$ \\ Tso-Yen $\mathrm{Mao}^{2}$ \\ 'Department of Family Medicine, \\ National Yang Ming Chiao Tung \\ University Hospital, Yilan, Taiwan, \\ Republic of China; ${ }^{2}$ Department of \\ Leisure Services Management, Chaoyang \\ University of Technology, Taichung, \\ Taiwan, Republic of China; ${ }^{3}$ Department \\ of Biomedical Sciences, Chang Gung \\ University, Taoyuan, Taiwan, Republic of \\ China
}

Purpose: Several osteoporosis drugs can continuously improve bone mass, but the impact on muscle mass is still unknown. This study aims to investigate how zoledronic acid monotherapy affected muscle mass in osteoporosis patients.

Patients and Methods: Patients from an osteoporosis database were divided into two groups in this retrospective cohort, case-control study: zoledronic acid-treated patients $(\mathrm{n}=$ $113)$ and a control group without osteoporosis treatment $(n=118)$. At four years, appendicular skeletal muscle mass (ASM) and appendicular skeletal muscle mass index (ASMI) were calculated using dual-energy X-ray absorptiometry. The differences in muscle mass between the groups were compared.

Results: At baseline, there was no difference in sex, ASM, ASMI, and bone mineral density between the zoledronic acid treatment group and the control group. The treatment group's skeletal muscle mass increased by $841 \mathrm{~g}$ in ASM and $0.35 \mathrm{~kg} / \mathrm{m}^{2}$ in ASMI after three years, while decreased in the control group.

Conclusion: This study for the first time demonstrated that that zoledronic acid is beneficial not only to the bone but also to muscle.

Keywords: muscle mass, osteoporosis, sarcopenia, zoledronic acid

\section{Introduction}

Sarcopenia is a loss of muscle strength and mass in older people that is a major predictor of falling risk and impaired ability to perform daily activities, often leading to disability, loss of independence, and death. ${ }^{1-3}$ The effects of sarcopenia on morbidity, mortality, and health-care costs in the elderly are now a major focus of research and public policy debate. ${ }^{4}$ Both the European Working Group on Sarcopenia in Older People (EWGSOP, updated in January 2019 by EWGSOP2) and the Asian Working Group on Sarcopenia (AWGS, updated in March 2020 by AWGS 2019) reached an international agreement that sarcopenia should be diagnosed using the walking ability, muscle strength, and muscle mass, and that intervention decision should be based on walking ability and muscle mass levels. ${ }^{5,6}$ However, muscle mass is the fundamental underlying criterion for diagnosis. Although increasing muscle mass is beneficial for sarcopenia, research on drugs that affect muscle mass has been limited to testosterone, selective androgen receptor molecules, ghrelin agonists, myostatin antibodies, activin IIR antagonists, angiotensin-converting enzyme inhibitors, beta antagonists, and a few others. ${ }^{7,8}$ Furthermore, these medicines continue to have effectiveness, safety, and dependability problems, rendering them inappropriate for clinical usage. ${ }^{9}$ Many osteoporosis medicines have been found to improve bone density and lower the incidence of fractures in the elderly. ${ }^{10,11}$ Teriparatide, a kind of parathyroid hormone, may have
Correspondence: Tso-Yen Mao Department of Leisure Services Management, Chaoyang University of Technology, 168, Jifeng E. Road, Wufeng District, Taichung, 4I3, Taiwan, Republic of China

Tel +886 $423323000 \# 7453$

Fax +886423742363

Email tymao.research@gmail.com 
anabolic effects on skeletal muscle and adipose tissue in addition to bone. ${ }^{12}$ Similarly, while vitamin D supplements may improve bone density, their effect on muscle mass and strength is still being researched. ${ }^{13}$ A previous study showed that combining alendronate and calcitriol improved grip strength but had no discernible effect on muscle mass in postmenopausal women. ${ }^{14}$ It is worth debating if some more strong bisphosphonates osteoporosis medications can not only enhance muscular strength but also muscle mass because they will play a more essential role in the treatment of sarcopenia. Intravenous zoledronic acid is a high-potency, nitrogen-containing bisphosphonate that is administered once a year and significantly reduces fracture risk in women with postmenopausal osteoporosis and a recent lowtrauma hip fracture. ${ }^{15}$ In vitro, zoledronic acid has the highest affinity for hydroxyapatite when compared to alendronate, ibandronate, and risedronate. ${ }^{16}$ Previous research has indicated that zoledronic acid increased muscular function and even muscle mass in healthy mice given chemotherapy, but its effect on sarcopenia has yet to be confirmed in humans. $^{17,18}$ As a result, we attempted to investigate the effect of zoledronic acid on muscle mass in osteoporosis patients.

\section{Materials and Methods}

\section{Study Design}

The study was designed as a case-control, retrospective cohort study. The bone density of the lumbar spine and hips was measured using dual-energy X-ray absorptiometry (DXA) (Prodigy; GE Medical Systems Lunar, Madison, WI, USA). DXA was also used to assess appendicular lean soft tissue (ASM, which is the sum of lean soft tissue from both arms and legs) and appendicular skeletal muscle index (ASMI, which is calculated as ASM divided by height square). This study included 1418 individuals with osteoporosis [T-score of $\leq-2.5$ obtained from bone mineral density (BMD) tests at the lumbar spine, femur neck, or total hip] in Yilan County, Taiwan, between May 2013 and April 2020. After excluding patients who used other antiosteoporotic drugs or alfacalcidol, those who received specific medications, including hormone, angiotensinconverting enzyme inhibitor, and beta antagonist, and those assessed by repeat DXA for less than 3 years or more than 5 years, a research group of 113 patients was chosen who received a $5 \mathrm{mg}$ zoledronic acid infusion once a year for three years and were evaluated using DXA, as well as a control group of 118 individuals who did not receive any

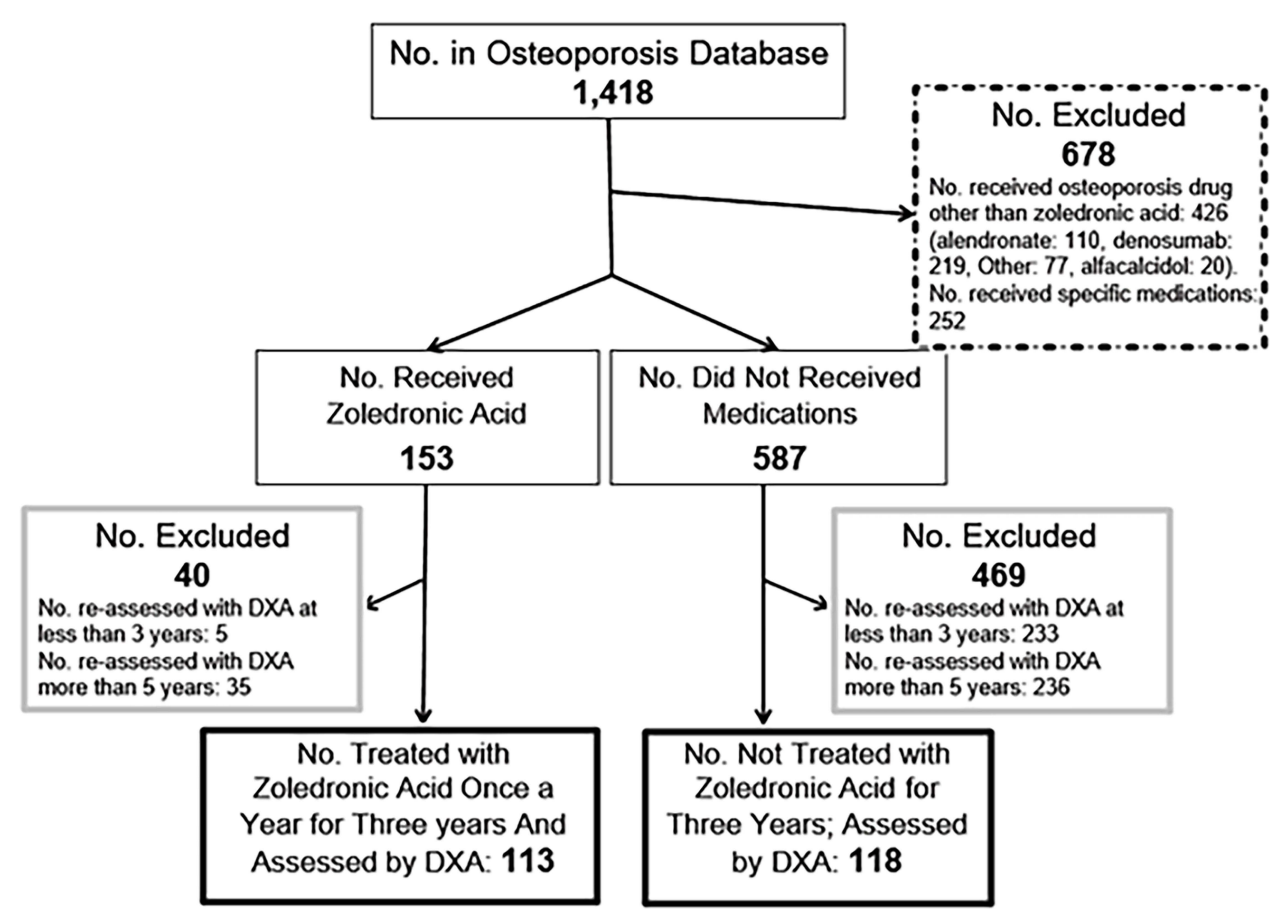

Figure I Flow chart for study subject selection.

Abbreviation: DXA, dual-energy X-ray absorptiometry. 
anti-osteoporotic medicines for three years and were similarly assessed using DXA (Figure 1).

\section{Ethics}

This study was approved by the Institutional Review Board (IRB) of the National Yang-Ming University Hospital (YMUH2020A023) in accordance with the Declaration of Helsinki. The study involves no prospectively collected data so there is no access to patients or opportunity to seek informed consent. A waiver of consent was approved by IRB as re-contacting this number of patients to obtain informed consent would be impracticable. The study is no greater than minimal risk and will have no direct impact on patient's rights and clinical care. Finally, we guarantee the confidentiality of all patient data.

\section{Statistical Analysis}

Descriptive statistics were used to summarize the basic characteristics. IBM SPSS Statistics for Windows, version 22 (IBM Corp., Armonk, N.Y., USA) was used to conduct formal statistical studies. The disparity in response variable change was compared between the research and control groups. To determine differences in the amount of change after three years, a general linear model with corrections for age, gender, height, weight, body mass index (BMI), and initial value for each item was used. The minimum total sample size in this study is 128 , with at least 64 subjects for each independent variable, for an effect size of $d=0.5$, power $=0.8$, and $\alpha=0.05$.

\section{Results}

There was no difference in mean age, BMI, ASM, ASMI, or BMD between the research and control groups when the patients' baseline characteristics were compared (Table 1). The change in muscle mass and bone mineral density over three years was compared after adjusting for height and weight, as well as the baseline value of each item. We discovered that the research group significantly improved in ASM, ASMI, and BMD (Table 2). Furthermore, according to a comparison of changes in muscle mass and BMD after three years, the levels of improvement in ASM and ASMI were positively correlated with BMD in the zoledronic acid-treated population $(\mathrm{r}=0.227, P=0.02)$, whereas in the control group, the amounts of change in ASM and ASMI were not associated with BMD $(\mathrm{r}=0.119, P=0.10)$.
Table I Baseline Characteristics of Participants in Research and Control Groups

\begin{tabular}{|l|c|c|c|}
\hline Characteristics & $\begin{array}{c}\text { Research } \\
\text { (Zoledronic } \\
\text { Acid) }\end{array}$ & Control & $P$ value \\
\hline Sample size (n) & 113 & 118 & \\
\hline Age, years, mean (SD) & $67.1(6.5)$ & $65.1(7.9)$ & 0.28 \\
\hline Women, \% (n) & $91.2 \%(103)$ & $88.1 \%(104)$ & 0.15 \\
\hline Height, cm, mean (SD) & $154.3(7.8)$ & $155.7(8.5)$ & 0.09 \\
\hline Weight, kg, mean (SD) & $48.3(8.1)$ & $49.5(9.9)$ & 0.12 \\
\hline BMI, kg/m², mean (SD) & $20.3(2.9)$ & $20.4(3.1)$ & 0.33 \\
\hline ASM, g, mean (SD) & $13,310(1899)$ & $13,899(1955)$ & 0.19 \\
\hline ASMl, kg/m², mean (SD) & $5.59(0.72)$ & $5.66(0.74)$ & 0.26 \\
\hline $\begin{array}{c}\text { BMD, g/cm }{ }^{2}, \text { mean (SD) } \\
\text { Lumbar spine }\end{array}$ & $\begin{array}{l}0.717(0.152) \\
\text { Femoral neck }\end{array}$ & $\begin{array}{l}0.665(0.091) \\
0.682(0.117)\end{array}$ & $\begin{array}{l}0.15 \\
0.19\end{array}$ \\
\hline
\end{tabular}

Abbreviations: ASM, appendicular skeletal muscle mass; ASMI, appendicular skeletal muscle mass index; BMD, bone mineral density; BMI, body mass index; SD, standard deviation.

Table 2 Comparison of Muscle and Bone Mineral Density Changes in the Research and Control Groups

\begin{tabular}{|c|c|c|c|}
\hline $\begin{array}{l}\text { Change after } \\
3.6 \text { Years } \\
\text { (SD 0.3) }\end{array}$ & $\begin{array}{c}\text { Zoledronic } \\
\text { Acid }(\mathbf{N}=|| 3)\end{array}$ & $\begin{array}{l}\text { Control } \\
(N=\mid 18)\end{array}$ & $\begin{array}{c}\text { Difference } \\
\text { Between- } \\
\text { Group }^{b}\end{array}$ \\
\hline \multirow[t]{2}{*}{$\begin{array}{l}\text { Difference in ASM, } \\
g, \text { mean (SD) }\end{array}$} & $+841(905)$ & $-107(1309)$ & $P=0.01^{b}$ \\
\hline & $P<0.00 I^{\mathrm{a}}$ & $P=0.12^{\mathrm{a}}$ & \\
\hline \multirow[t]{2}{*}{$\begin{array}{l}\text { Difference in } \\
\text { ASMI, } \mathrm{kg} / \mathrm{m}^{2}, \\
\text { mean (SD) }\end{array}$} & $+0.35(0.69)$ & $-0.154(0.546)$ & $P=0.03^{b}$ \\
\hline & $P=0.002^{\mathrm{a}}$ & $P=0.21^{\mathrm{a}}$ & \\
\hline \multicolumn{4}{|l|}{$\begin{array}{l}\text { Difference in } \\
\text { BMD, } \mathrm{g} / \mathrm{cm}^{2} \text {, } \\
\text { mean (SD) }\end{array}$} \\
\hline \multirow[t]{2}{*}{ Lumbar spine } & $+0.083(0.043)$ & $-0.007(0.021)$ & $P=0.01^{b}$ \\
\hline & $P<0.00 I^{a}$ & $P=0.14^{\mathrm{a}}$ & \\
\hline \multirow[t]{2}{*}{ Femoral neck } & $+0.047(0.015)$ & $-0.012(0.017)$ & $P=0.03^{b}$ \\
\hline & $P<0.00 I^{a}$ & $P=0.03^{a}$ & \\
\hline
\end{tabular}

Notes: ${ }^{2}$ The paired $t$-test revealed a difference when compared to the baseline. ${ }^{\mathrm{b}} \mathrm{A} t$-test was used to compare groups.

Abbreviations: ASM, appendicular skeletal muscle mass; ASMI, appendicular skeletal muscle mass index; SD, standard deviation. 


\section{Discussion}

This is the first study to suggest that zoledronic acid treatment may help improve muscle mass. Muscle and bone support independence in the elderly but decline with age. As a result, among the elderly, sarcopenia and osteoporosis are relatively common. ${ }^{19}$ Sarcopenia and osteoporosis raise the risk of falling and may lead to a fragility fracture, such as a hip fracture, which is a lifethreatening event with high morbidity and mortality. ${ }^{20}$ In women with postmenopausal osteoporosis, zoledronic acid increases bone mass and has been linked to a significant reduction in the risk of vertebral, hip, and nonvertebral fractures, but its clinical effect on muscle has remained unknown. ${ }^{15,21}$ Although the effect on muscle strength and performance could not be investigated in this retrospective case-control study, it is suggested for the first time that zoledronic acid alone may produce clinical improvements in muscle mass.

The effects of bisphosphonates on muscle growth and function in osteoporosis patients are debatable. By reducing bone loss, zoledronic acid treatment may protect mice against carboplatin- or cisplatin-induced muscle weakening. ${ }^{17,18}$ The release of soluble mediators (known as "osteokines") by bone-secreted substances appears to impact skeletal muscle beyond the mechanical connection in loading. ${ }^{22}$ Previous research discovered that bisphosphonates inhibited muscle atrophy while promoting muscle regenerative capacity via SIRT3 downregulation. ${ }^{23}$ Another study found that pamidronate, a bisphosphonate, improved both bone (increased bone growth and strength) and skeletal muscle function (increased grip strength) in Mdx mice, an animal model used as a surrogate for Duchenne muscular dystrophy. ${ }^{24}$ The mechanisms of bisphosphonate on muscle atrophy have been suggested to the stimulation of hypertrophic myotube formation. ${ }^{23}$

The present study demonstrates for the first time that zoledronic acid can significantly improve not only bone mineral density but also muscle mass after three years of treatment. However, there are some limitations to this retrospective case-control study. Because sarcopenia diagnostic criteria such as muscle strength and walking speed were not assessed, it is unknown whether zoledronic acid affects these performance objects. Further prospective studies for the effect of zoledronic acid on osteoporosis-related or agingrelated skeletal muscle wasting needs to be considered.

\section{Conclusion}

This study revealed that, in addition to improving bone density in osteoporosis patients, three years of zoledronic acid treatment may increase appendicular skeletal muscle mass index, which is necessary for sarcopenia diagnosis.

\section{Acknowledgments}

The authors acknowledge the efforts of the Department of Information Management of National Yang Ming Chiao Tung University Hospital at Yilan for collecting clinical data and providing administrative supports.

\section{Author Contributions}

The authors confirm contribution to the paper as follows: study conception and design: Tso-Yen Mao, Chun-Feng Huang; data collection: Chun-Feng Huang; analysis and interpretation of results: Tso-Yen Mao, Ming-Shi Shiao, Chun-Feng Huang; draft manuscript preparation: ChunFeng Huang. All authors made a significant contribution to the work reported, whether that is in the conception, study design, execution, acquisition of data, analysis and interpretation, or in all these areas; took part in drafting, revising or critically reviewing the article; gave final approval of the version to be published; have agreed on the journal to which the article has been submitted; and agree to be accountable for all aspects of the work.

\section{Funding}

The authors received no financial support for the research, authorship, and/or publication of this article.

\section{Disclosure}

The authors report no conflicts of interest in this work.

\section{References}

1. Cruz-Jentoft AJ, Sayer AA. Sarcopenia. Lancet. 2019;393 (10191):2636-2646. doi:10.1016/S0140-6736(19)31138-9

2. Marzetti E, Calvani R, Tosato M, et al. Sarcopenia: an overview. Aging Clin Exp Res. 2017;29(1):11-17. doi:10.1007/s40520-016-0704-5

3. Shafiee G, Keshtkar A, Soltani A, Ahadi Z, Larijani B, Heshmat R. Prevalence of sarcopenia in the world: a systematic review and meta-analysis of general population studies. $J$ Diabetes Metab Disord. 2017;21:2017. doi:10.1186/s40200-017-0302-x

4. Liu P, Hao Q, Hai S, Wang H, Cao L, Dong B. Sarcopenia as a predictor of all-cause mortality among community-dwelling older people: a systematic review and meta-analysis. Maturitas. 2017;103:16-22. doi:10.1016/j.maturitas.2017.04.007

5. Cruz-Jentoft AJ, Bahat G, Bauer J, et al. Sarcopenia: revised European consensus on definition and diagnosis. Age Ageing. 2019;48(1):16-31. doi:10.1093/ageing/afy169 
6. Chen LK, Woo J, Assantachai P, et al. Asian Working group for sarcopenia: 2019 consensus update on sarcopenia diagnosis and treatment. J Am Med Dir Assoc. 2020;21(3):300-307.e2. doi:10. 1016/j.jamda.2019.12.012

7. Morley JE. Pharmacologic options for the treatment of sarcopenia. Calcif Tissue Int. 2016;98(4):319-333. doi:10.1007/s00223-015-0022-5

8. Morley JE. Hormones and Sarcopenia. Curr Pharm Des. 2017;23 (30):4484-4492. doi:10.2174/1381612823666161123150032

9. Landi F, Calvani R, Cesari M, et al. Sarcopenia: an Overview on current definitions, diagnosis and treatment. Curr Protein Pept Sci. 2018;19(7):633-638. doi:10.2174/1389203718666170607113459

10. Black DM, Rosen CJ. Clinical practice. postmenopausal osteoporosis. $N$ Engl J Med. 2016;374(3):254-262. doi:10.1056/ NEJMcp 1513724

11. Fink HA, MacDonald R, Forte ML, et al. Long-Term drug therapy and drug discontinuations and holidays for osteoporosis fracture prevention: a systematic review. Ann Intern Med. 2019;171(1): 37-50. doi:10.7326/M19-0533

12. Sato C, Miyakoshi N, Kasukawa Y, et al. Teriparatide and exercise improve bone, skeletal muscle, and fat parameters in ovariectomized and tail-suspended rats. J Bone Miner Metab. 2021;39(3):385-395. doi:10.1007/s00774-020-01184-0

13. Cangussu LM, Nahas-Neto J, Orsatti CL, Bueloni-Dias FN, Nahas EA. Effect of vitamin D supplementation alone on muscle function in postmenopausal women: a randomized, double-blind, placebo-controlled clinical trial. Osteoporos Int. 2015;26(10):24 13-2421. doi:10.1007/s00198-015-3151-9

14. Park JH, Park KH, Cho S, et al. Concomitant increase in muscle strength and bone mineral density with decreasing IL-6 levels after combination therapy with alendronate and calcitriol in postmenopausal women. Menopause. 2013;20(7):747-753. doi:10.1097/GME.0b0 13 e31827cabca

15. Liu M, Guo L, Pei Y, et al. Efficacy of zoledronic acid in treatment of osteoporosis in men and women-a meta-analysis. Int J Clin Exp Med. 2015;8(3):3855-3861.
16. Drake MT, Clarke BL, Khosla S. Bisphosphonates: mechanism of action and role in clinical practice. Mayo Clin Proc. 2008;83 (9):1032-1045. doi:10.4065/83.9.1032

17. Hain BA, Jude B, Xu H, et al. Zoledronic Acid Improves Muscle Function in Healthy Mice Treated with Chemotherapy. J Bone Miner Res. 2020;35(2):368-381. doi:10.1002/jbmr.3890

18. Essex AL, Pin F, Huot JR, Bonewald LF, Plotkin LI, Bonetto A. Bisphosphonate Treatment Ameliorates Chemotherapy-Induced Bone and Muscle Abnormalities in Young Mice. Front Endocrinol (Lausanne). 2019;10:809. doi:10.3389/fendo.2019.00809

19. Curtis E, Litwic A, Cooper C, Dennison E. Determinants of Muscle and Bone Aging. J Cell Physiol. 2015;230(11):2618-2625. doi:10. 1002/jcp. 25001

20. Greco EA, Pietschmann P, Migliaccio S. Osteoporosis and Sarcopenia Increase Frailty Syndrome in the Elderly. Front Endocrinol. 2019;10:255. doi:10.3389/fendo.2019.00255

21. Boonen S, Black DM, Colón-Emeric CS, et al. Efficacy and safety of a once-yearly intravenous zoledronic acid $5 \mathrm{mg}$ for fracture prevention in elderly postmenopausal women with osteoporosis aged 75 and older. $\mathrm{J} \mathrm{Am}$ Geriatr Soc. 2010;58(2):292-299. doi:10.1111/j.1532-5415.2009.02673.x

22. Kirk B, Feehan J, Lombardi G, Duque G. Muscle, Bone, and Fat Crosstalk: the Biological Role of Myokines, Osteokines, and Adipokines. Curr Osteoporos Rep. 2020;18(4):388-400. doi:10.10 07/s11914-020-00599-y

23. Chiu HC, Chiu CY, Yang RS, Chan DC, Liu SH, Chiang CK. Preventing muscle wasting by osteoporosis drug alendronate in vitro and in myopathy models via sirtuin-3 down-regulation. J Cachexia Sarcopenia Muscle. 2018;9(3):585-602. doi:10.1002/jcsm.12289

24. Yoon SH, Sugamori KS, Grynpas MD, Mitchell J. Positive effects of bisphosphonates on bone and muscle in a mouse model of Duchenne muscular dystrophy. Neuromuscul Disord. 2016;26(1):73-84. doi:10.1016/j.nmd.2015.09.015
Drug Design, Development and Therapy

\section{Publish your work in this journal}

Drug Design, Development and Therapy is an international, peerreviewed open-access journal that spans the spectrum of drug design and development through to clinical applications. Clinical outcomes, patient safety, and programs for the development and effective, safe, and sustained use of medicines are a feature of the journal, which has also

\section{Dovepress}

been accepted for indexing on PubMed Central. The manuscript management system is completely online and includes a very quick and fair peer-review system, which is all easy to use. Visit http://www. dovepress.com/testimonials.php to read real quotes from published authors. 